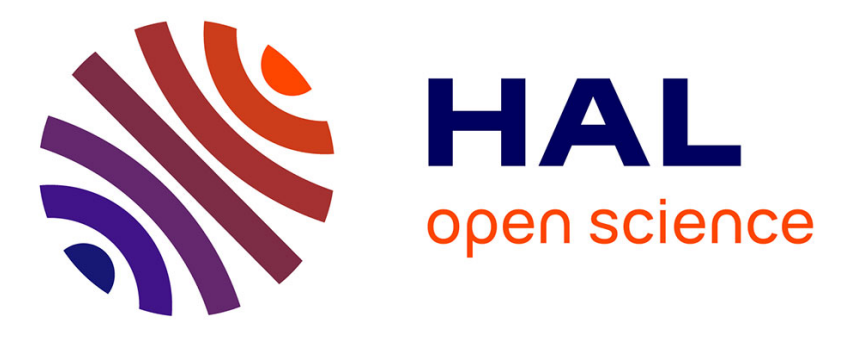

\title{
How life history influences population dynamics in fluctuating environments.
}

Bernt-Erik Sæther, Tim Coulson, Vidar Grøtan, Steinar Engen, Romain Altwegg, Kenneth B. Armitage, Christophe Barbraud, Peter H. Becker, Daniel T. Blumstein, F Stephen Dobson, et al.

\section{To cite this version:}

Bernt-Erik Sæther, Tim Coulson, Vidar Grøtan, Steinar Engen, Romain Altwegg, et al.. How life history influences population dynamics in fluctuating environments.. American Naturalist, 2013, 182 (6), pp.743-759. 10.1086/673497 . hal-00853677

\section{HAL Id: hal-00853677 https://hal.science/hal-00853677}

Submitted on 26 May 2021

HAL is a multi-disciplinary open access archive for the deposit and dissemination of scientific research documents, whether they are published or not. The documents may come from teaching and research institutions in France or abroad, or from public or private research centers.
L'archive ouverte pluridisciplinaire HAL, est destinée au dépôt et à la diffusion de documents scientifiques de niveau recherche, publiés ou non, émanant des établissements d'enseignement et de recherche français ou étrangers, des laboratoires publics ou privés. 


\title{
How Life History Influences Population Dynamics in Fluctuating Environments
}

\author{
Bernt-Erik Sæther, ${ }^{1, \star}$ Tim Coulson, ${ }^{2}$ Vidar Grøtan, ${ }^{1}$ Steinar Engen, ${ }^{3}$ Res Altwegg, \\ Kenneth B. Armitage, ${ }^{5}$ Christophe Barbraud, ${ }^{6}$ Peter H. Becker, ${ }^{7}$ Daniel T. Blumstein, ${ }^{8}$ \\ F. Stephen Dobson, ${ }^{9,10}$ Marco Festa-Bianchet, ${ }^{11}$ Jean-Michel Gaillard, ${ }^{12}$ Andrew Jenkins, ${ }^{13}$ \\ Carl Jones, ${ }^{14,15}$ Malcolm A. C. Nicoll, ${ }^{16}$ Ken Norris, ${ }^{16}$ Madan K. Oli, ${ }^{17}$ Arpat Ozgul, ${ }^{17,18}$ and \\ Henri Weimerskirch ${ }^{6}$
}

1. Department of Biology, Centre for Biodiversity Dynamics, Norwegian University of Science and Technology, Trondheim, NO-7491 Norway; 2. Department of Zoology, University of Oxford, South Parks Road, Oxford OX1 3PS, United Kingdom;

3. Department of Mathematical Sciences, Centre for Biodiversity Dynamics, Norwegian University of Science and Technology, Trondheim, NO-7491 Norway; 4. South African National Biodiversity Institute, Kirstenbosch Research Centre, Claremont 7735, and Department of Biological Sciences and Department of Statistical Sciences, Animal Demography Unit, University of Cape Town, Rondebosch 7701, South Africa; 5. Department of Ecology and Evolutionary Biology, University of Kansas, Lawrence, Kansas 66045; 6. Centre d'Etudes Biologiques de Chizé, CNRS, Unités Propres de Recherche 1934, 79360 Villiers en Bois, France; 7. Institute of Avian Research "Vogelwarte Helgoland," Wilhelmshaven 26386, Germany; 8. Department of Ecology and Evolutionary Biology, University of California, Los Angeles, California 90095; 9. Centre d’Ecologie Fonctionnelle et Évolutive, Unités Mixtes de Recherche 5175 du CNRS, 1919 route de Mende, F-34293 Montpellier, Cedex 5, France; 10. Department of Biological Sciences, Auburn University, Auburn, Alabama 36849; 11. Département de Biologie, Université de Sherbrooke, Quebec J1K 2R1, Canada; 12. Biométrie et Biologie Évolutive, Unités Mixtes de Recherche, CNRS, 5558 Laboratoire de Biométrie et Biologie Évolutive, Université Claude Bernard Lyon 1, Bâtiment Grégor Mendel, 43 boulevard du 11 novembre 1918, 69622 Villeurbanne Cedex, France; 13. Percy FitzPatrick Institute of African Ornithology, Department of Science and Technology, National Research Foundation Centre of Excellence, University of Cape Town, Rondebosch 7701, South Africa; 14. Mauritian Wildlife Foundation, Grannum Road, Vacoas, Mauritius; 15. Durrell Wildlife Conservation Trust, Les Augrès Manor, Trinity, Jersey JE3 5BP, Channel Island; 16. Centre for Agro-Environmental Research, School of Agriculture-Environmental Research, School of Agriculture, Policy, and Development, University of Reading, Reading RG6 6AR, United Kingdom; 17. Department of Wildlife Ecology and Conservation, University of Florida, Gainesville, Florida 32611; 18. Institute of Evolutionary Biology and Environmental Studies, University of Zurich, Zurich, Switzerland

Submitted December 17, 2012; Accepted June 19, 2013; Electronically published October 25, 2013

\begin{abstract}
AвSTRACT: A major question in ecology is how age-specific variation in demographic parameters influences population dynamics. Based on long-term studies of growing populations of birds and mammals, we analyze population dynamics by using fluctuations in the total reproductive value of the population. This enables us to account for random fluctuations in age distribution. The influence of demographic and environmental stochasticity on the population dynamics of a species decreased with generation time. Variation in age-specific contributions to total reproductive value and to stochastic components of population dynamics was correlated with the position of the species along the slow-fast continuum of life-history variation. Younger age classes relative to the generation time accounted for larger contributions to the total reproductive value and to demographic stochasticity in "slow" than in "fast" species, in which many age classes contributed more equally. In contrast, fluctuations in population growth rate attributable to stochastic environmental variation involved a larger proportion of all age classes independent of
\end{abstract}

\footnotetext{
* Corresponding author; e-mail: bernt.erik.sather@bio.ntnu.no.
}

Am. Nat. 2013. Vol. 182, pp. 743-759. (c) 2013 by The University of Chicago. 0003-0147/2013/18206-54347\$15.00. All rights reserved.

DOI: $10.1086 / 673497$ life history. Thus, changes in population growth rates can be surprisingly well explained by basic species-specific life-history characteristics.

Keywords: demographic stochasticity, environmental stochasticity, life history, reproductive value, stochastic demography.

\section{Introduction}

Species display a wide array of life histories (Stearns 1992; Roff 2002) with a pattern of covariation among traits that positions the species along a slow-fast continuum of lifehistory variation (Stearns 1983; Gaillard et al. 1989; Promislow and Harvey 1990; Sæther and Bakke 2000). Species at the fast end of this continuum mature early in life, produce many offspring at each reproductive event, but have short life expectancy. The slow end includes longlived species with delayed maturity and small litter or brood sizes that are often restricted to a single offspring. The position of the species along this continuum is closely correlated to its generation time (Gaillard et al. 2005). In 
some taxa, such as mammals, it is also linked to variation in body mass and development time (Millar and Zammuto 1983; Dobson and Oli 2007).

Patterns of life-history covariation are also associated with differences in age-specific vital rates. For instance, early comparative analyses suggested that interspecific differences in age-specific survival could be classified into some distinct types (Pearl and Miner 1935), constraining the structure of life tables (Deevey 1947). These early advances led to a new research field in evolutionary ecology that focuses on how age-specific variation in vital rates affects evolution of life history (see reviews in Charlesworth 1994, Caswell 2001, and Rauser et al. 2009). However, the implications of life history for population dynamics are much less well understood.

Patterns of age-specific variation in vital rates affect population dynamics. Comparative studies have revealed large interspecific differences in both the magnitude of variability and patterns of population fluctuations (Pimm and Redfearn 1988; Ariño and Pimm 1995; Sæther and Engen 2002; Sæther et al. 2002; Lande et al. 2003). However, our understanding of how basic species-specific life-history characteristics affect this variation is limited, because it requires models that include both deterministic changes over long periods and stochastic influences on fluctuations in population size. An important advance in modeling agestructured populations was provided by Leslie's (1945, 1948) introduction of matrix models. Temporal variation in expected values of population size and age distribution in subsequent generations can be calculated from a projection matrix whose elements are age-specific values of reproduction and survival. The original formulation of the Leslie model did not include stochasticity. Later, Pollard (1966) and Goodman (1967) introduced demographic stochasticity in age-structured models, in which each individual's contribution to future generations is a random independent variable with an identical distribution for each year and every age class. Lewontin and Cohen (1969) and Cohen $(1977,1979)$ developed another class of stochastic age-structured models that included environmental stochasticity (temporal variation in the environment affecting the whole or parts of the population in a similar way) based on the theory of stochastic matrices, in which the projection matrices are some temporal sequence of random matrices with distributions independent of the population vector. This approach was further extended by Tuljapurkar $(1982 b, 1990)$, who derived an important firstorder approximation for how environmental stochasticity reduces the long-term growth rate of the population. The influences of both demographic and environmental stochasticity were included in models by Engen et al. (2005) of the dynamics of age-structured populations using a diffusion approximation that generalized the previous ap- proach of Lande and Orzack (1988). Unfortunately, all of these models require estimates of a large number of parameters, seriously restricting their practical applicability.

In addition to model complexity, the relationship between life history and fluctuations in population size is complicated by age dependence in life histories, leading to multiple time delays in the population dynamics and transient fluctuations in age structure even with a constant environment (Haridas and Tuljapurkar 2007). Furthermore, demographic and environmental stochasticity will also cause random variation in age distribution (Caswell 2001; Lande et al. 2003). In populations in which survival and fertility rates vary with age, these two types of stochasticity generate a correlation between population growth at time $t+1$ and $t$, because the number of individuals of age $a+1$ at time $t+1$ is dependent upon the number of individuals of age $a$ at time $t$ (Coulson et al. 2001). The strength of this temporal autocorrelation varies across species to an unknown extent (Caswell 2001), which complicates cross-species comparative analyses of the role of environmental and demographic stochasticity on population dynamics.

Here, we aim to identify general patterns that link lifehistory variation and population dynamics in fluctuating environments by removing temporal autocorrelations in population fluctuations using parameters that can be estimated from individual-based demographic data. Recent theoretical advances have shown how this can be achieved by calculating the long-run stochastic growth rate using the total reproductive value of the population, $V$, rather than time series of population size, $N$ (Engen et al. 2007, 2009b). The reproductive value of an age class $a$ is the contribution of individuals aged $a$ to future population sizes, relative to the contributions from individuals in the other age classes (Roughgarden 1979). The total reproductive value of the population is the sum of reproductive values of all individuals within the population (Engen et al. 2009b) and consequently depends on the age structure. Fisher (1930) showed that $V$ grows exactly exponentially in deterministic density-independent models of population growth, which is the case for $N$ only when the population is at the stable age distribution (e.g., fig. 3.1 in Lande et al. 2003). Engen et al. $(2007,2009 b)$ extended this approach to stochastic models, defining individual reproductive value as the stochastic contribution of an individual to the total reproductive value of the population at the next time step. Although fluctuations in age structure can generate temporal autocorrelations in annual changes in population size, the total reproductive value exhibits little or no autocorrelation (Engen et al. 2007, 2009b).

Here, we use long-term individual-based studies to investigate how age-specific variation in demographic char- 
acteristics contributes to growth of populations of birds and mammals with different life histories after accounting for generation time. We then examine whether these patterns are correlated with the position of the species along the slow-fast continuum of life-history variation (Stearns 1983; Gaillard et al. 1989; Promislow and Harvey 1990; Sæther and Bakke 2000; Dobson and Oli 2007). Our aim is to identify critical stages of the life history (Charlesworth 1972) most strongly influencing stochastic variation in population growth rates and examine whether these are different from those affecting the long-term changes in mean population size.

\section{The Model}

The long-run population growth rate from time step 1 to $T$ (Tuljapurkar and Orzack 1980; Tuljapurkar et al. 2003) can, according to Sæther et al. (2007), be written as

$$
\begin{aligned}
s & =\frac{1}{T-1} \sum_{t=1}^{T-1}\left[\ln (V(t+1))-\ln (V(t))+\frac{\sigma_{\mathrm{d}}^{2}}{2 N(t)}\right] \\
& \approx r-\frac{\sigma_{\mathrm{e}}^{2}}{2}
\end{aligned}
$$

where $r$ is the mean population growth rate on the logarithmic scale, $N(t)$ is the population size in year $t, \sigma_{\mathrm{e}}^{2} / 2$ describes how environmental stochasticity contributes to the long-run stochastic growth rate, and $\sigma_{\mathrm{d}}^{2} / 2 N(t)$ quantifies how the influence of demographic stochasticity decreases with increasing population size. This ignores any effect of density dependence. Much as the total reproductive value, $V$, is dependent on age-specific patterns of survival and fertility, so too are the demographic and environmental variances, $\sigma_{\mathrm{d}}^{2}$ and $\sigma_{\mathrm{e}}^{2}$ (Engen et al. 2009b). Both these variance components and the total reproductive value can be partitioned further, assuming no density dependence, into age class-specific survival and fertility contributions and a covariance between them (Tuljapurkar 1990; Benton et al. 1995; Caswell 2001; Gaillard and Yoccoz 2003; Engen et al. 2005; Morris et al. 2006).

Let $n=\left(n_{1}, n_{2}, \ldots n_{k}\right)^{\mathrm{T}}$ be a column vector of the number of individuals in the different age classes, where $\mathrm{T}$ denotes the transpose of a vector, and let the population vector the next year be $n+\Delta n=L n$, where $L$ is a stochastic projection matrix (Caswell 2001). We consider only the female segment of the population and assume prebreeding census so that the subdiagonal defines the survivals of age classes 1 to $k-1$, and the first row of $L$ defines their age-specific fecundity (i.e., the number of offspring recruited by females of different age classes into the population). The last age class $k$ may be a terminal class so that individuals in this class survive with proba- bility $L_{k k}$ to remain in the same class. The expected projection matrix $l=\mathrm{E} L$ has the real dominant eigenvalue of $\lambda$ and right and left eigenvectors $u$ (column vector) defined by $l u=\lambda u$ and $v$ (row vector) defined by $v l=$ $\lambda v$. These eigenvectors are commonly scaled (Engen et al. $2009 b)$ so that $\sum u_{i}=1$ and $v u=\sum u_{i} v_{i}=1$. Then $u$ is the stable age distribution for the deterministic model defined by $l$, and the components of $v$ are the reproductive values for the different age classes (Caswell 1978). The sum of reproductive values of all individuals $V=v n=$ $\sum n_{i} v_{i}$ is called the total reproductive value of the population. This equals the total population size $N$ if the population is exactly at its stable age distribution, and generally $N-V$ fluctuates around zero. The Fisherian stable age distribution (Engen et al. 2011) is simply $u_{i} v_{i}$, expressing how the total reproductive value $V$ is distributed among age classes if the population is at the stable age distribution $u$.

For a finite population, the first row of the projection matrix is the mean number of female offspring recruited into the breeding population by females in different age classes, whereas the lower subdiagonal elements are the fraction of surviving individuals. Writing $B_{i}$ for the number of female offspring recruited into the breeding population (i.e., recorded in the population at the age at maturity or later) by an individual in age class $i$ and $J_{i}$ for its survival, defined as 1 if it survives and otherwise 0 , the individual reproductive value for a given female is defined (Engen et al. 2009b) as

$$
W_{i}=B_{i} v_{1}+J_{i} v_{i+1},
$$

where $v_{i+1}$ by definition equals $v_{i}$. This is the contribution from a single female to the total reproductive value the next year. The $W_{i}$ values are random variables, and their distribution within and among years defines the demographic and environmental variance required to describe the dynamics of the population (Engen et al. 2009b). Writing $Z$ for the environment in a given year, possibly a large vector, we define the demographic variance components $f_{\mathrm{d} i}=\mathrm{E} \operatorname{Var}\left(B_{i} \mid Z\right), s_{\mathrm{d} i}=\mathrm{E} \operatorname{Var}\left(J_{i} \mid Z\right)$, and $c_{\mathrm{d} i}=$ $\mathrm{E} \operatorname{Cov}\left(B_{i}, J_{i} \mid Z\right)$, where the expectations are temporal means, and the variances and the covariance refer to the distribution within a year. The demographic variance is then given (Engen et al. 2009b) by

$$
\sigma_{\mathrm{d}}^{2}=\sum u_{i}\left(f_{\mathrm{d} i} v_{1}^{2}+s_{\mathrm{di}} v_{i+1}^{2}+2 c_{\mathrm{d} i} v_{1} v_{i+1}\right)=\sum u_{i} \sigma_{\mathrm{di}}^{2},
$$

where the age-specific demographic variance component $\sigma_{\mathrm{d} i}^{2}$ is defined by the $i$ th term of the sums. The three additive components of $\sigma_{\mathrm{d} i}^{2}$ then become 


$$
\begin{aligned}
& \sigma_{\mathrm{dif}}^{2}=f_{\mathrm{d} i} v_{1}^{2}, \\
& \sigma_{\mathrm{d} i \mathrm{~s}}^{2}=s_{\mathrm{d} i} v_{i+1}^{2},
\end{aligned}
$$

and

$$
\sigma_{\mathrm{difs}}^{2}=2 c_{\mathrm{d} i} v_{1} v_{i+1} .
$$

Thus, the components of the demographic variance due to fecundity and survival alone are $\sigma_{\mathrm{df}}^{2}$ and $\sigma_{\mathrm{ds}}^{2}$, respectively.

Environmental stochasticity acts on all individuals of the population (Lewontin and Cohen 1969; May 1973; Cohen 1977; Turelli 1977). In a given year, the mean fecundity of age class $i, \mathrm{E}\left(B_{i} \mid Z\right)$ will generally differ from the overall mean $\mathrm{E}\left(B_{i}\right)$, and the deviations $\mathrm{E}\left(B_{i} \mid Z\right)$ $\mathrm{E}\left(B_{i}\right)$ will undergo temporal fluctuations with zero mean. By these types of environmental deviations, we define $f_{\text {eij }}=\operatorname{Cov}\left[\left(\mathrm{E}\left(B_{i} \mid Z\right)-\mathrm{E}\left(B_{i}\right)\right),\left(\mathrm{E}\left(B_{j} \mid Z\right)-\mathrm{E}\left(B_{j}\right)\right)\right]$, where the covariance refers to temporal variation. Similarly, by replacing $B_{i}$ by $J_{i}$ we define $s_{\mathrm{e} i j}$. Finally, there will be temporal environmental covariance components between fecundity and survival, defined as $c_{\mathrm{e} i j}=\operatorname{Cov}\left[\left(\mathrm{E}\left(J_{i} \mid Z\right)-\mathrm{E}\left(J_{i}\right)\right)\right.$, $\left.\left(\mathrm{E}\left(B_{j} \mid Z\right)-\mathrm{E}\left(B_{j}\right)\right)\right]$. Using these definitions, the environmental variance can be written as

$$
\begin{aligned}
\sigma_{\mathrm{e}}^{2} & =\sum_{i j} u_{i} u_{j}\left[s_{\mathrm{e} i j} v_{i+1} v_{j+1}+f_{\mathrm{e} i j} v_{1}^{2}+c_{\mathrm{e} i j}\left(v_{i+1}+v_{j+1}\right) v_{1}\right] \\
& =\sum_{i j} u_{i} u_{j} \tau_{\mathrm{e} i j},
\end{aligned}
$$

where the age-specific component $\tau_{\text {eij }}$ is defined by the $i j$ term of the equation. From this, we define the environmental component for a single age class as the sum over the covariances with all the age classes, that is, $\tau_{\mathrm{e} i}=$ $\sum u_{j} \tau_{\mathrm{eij}}$. Then, the total environmental variance takes the same form as the total demographic variance,

$$
\sigma_{\mathrm{e}}^{2}=\sum_{i} u_{i} \tau_{\mathrm{e} i}
$$

which can be partitioned (Engen et al. 2009b) into additive components from fecundity $\sigma_{\mathrm{ef}}^{2}$ and survival $\sigma_{\mathrm{es}}^{2}$ as well as the covariance between them.

\section{Estimation Procedures}

We employ the estimation procedure detailed by Engen et al. $(2009 b)$. To estimate the variance components of stochasticity, we estimate the mean projection matrix $l$ by estimating each element as the mean of all observed vital rates within and among years. The eigenvectors of the estimated matrix then serve as estimates of the actual eigenvectors $u$ and $v$. The complete data set is records of survival and reproduction, $\left(J_{i m t}, B_{i m t}\right)$, for ages $i=$ $1,2, \ldots, k$, in years $t=1,2, \ldots T$, and individuals $m=$ $1,2, \ldots n_{i t}$, where $n_{i t}$ is the number of individuals in age class $i$ recorded at year $t$. The corresponding individual reproductive values are $W_{i m t}=J_{i m t} v_{1}+B_{i m t} \nu_{i+1}$. One advantage by our approach is that it requires only data of a sample of individuals from the population (Engen et al. $2009 b$ ). We assume that individuals were present in all years between the first and last year but did not reproduce in the years not recorded in the population. However, our estimates of mortality still exclude some individuals that are alive but do not reproduce. We assume that those individuals have a negligible influence on the population dynamics because of high recapture rates of individuals in most of the studies included in our analyses (sometimes even close to 1; Barbraud et al. 1999; Catchpole et al. 2004). Furthermore, the pattern of variation in the survival estimates included as elements in the projection matrix $l$ was, in several of the populations, similar to the agedependent differences in survival rates revealed by capturerecapture analyses (e.g., Weimerskirch 1992; Catchpole et al. 2004; Gaillard et al. 2004; Pardo et al. 2013).

We then consider a given year $t$ with environment $Z$ and estimate the demographic variance component conditioned on $Z$, that is,

$$
\hat{\sigma}_{\mathrm{di}}^{2}(Z)=\operatorname{Var}\left(W_{i} \mid Z\right)=\frac{1}{n_{i t}-1} \sum_{m=1}^{n_{i t}}\left(W_{i m t}-\overline{W_{i t}}\right)^{2}
$$

where $\overline{W_{i t}}=n_{i t}^{-1} \sum_{m=1}^{n_{i t}} W_{i m t}$. The estimate $\hat{\sigma}_{\mathrm{d} i}^{2}$ of $\sigma_{\mathrm{d} i}^{2}$ is then simply given by the weighted mean of the above estimates over years with at least two records from individuals in the actual age class with weights $n_{t i}-1$. Finally, the estimate of the total demographic variance is

$$
\hat{\sigma}_{\mathrm{d}}^{2}=\sum u_{i} \hat{\sigma}_{\mathrm{d} i}^{2}
$$

Engen et al. (2009b) showed that each product of the type $1 / 2\left(W_{i m t}-W_{i m^{\prime} t^{\prime}}\right)\left(W_{j q t}-W_{j q^{\prime} t^{\prime}}\right)$ has expectation $\tau_{\text {eij }}$. Here, $t \neq t^{\prime}$ and $i$ and $j$ may refer to any age classes. If $i=j$, we must require that $q \neq m$ and $q^{\prime} \neq m^{\prime}$, whereas the last subscript otherwise may refer to any observed individual in the class. An efficient unbiased estimator for $\tau_{\text {eij }}$ is obtained as the mean value of these products over all possible combinations of $t \neq t^{\prime}$ and all combinations of the second subscript. Finally, the environmental variance is estimated using

$$
\hat{\sigma}_{\mathrm{e}}^{2}=\sum_{i j} u_{i} u_{j} \tau_{\mathrm{e} i j} .
$$

Generation time is defined as the mean age of mothers of newborn female offspring when the population is at the stable age distribution (Leslie 1966; Caswell 2001; Gaillard et al. 2005). In this study, data on long-lived bird species do not include information about survival prior to onset of reproduction. Hence, we estimate generation time as 


$$
G=\alpha+\frac{p}{1-p}
$$

(Lande et al. 2003), where $\alpha$ is the modal age at first reproduction and $p$ is the mean adult survival rate, weighted by the stable age distribution and assuming a constant population size.

\section{Data}

To parameterize the model described above, we needed individual-based age-specific survival and fecundity records across multiple years as well as time series of population size for natural populations thought to be well below carrying capacity. We sourced suitable demographic data from 12 studies (table 1) during periods with no detectable density dependence in the population dynamics, as revealed by simply regressing change in population size $\Delta N$ on $N$ (Royama 1992).

The bighorn sheep (Ovis canadensis) population was located at Ram Mountain $\left(52^{\circ} \mathrm{N}, 115^{\circ} \mathrm{W}\right)$, Alberta, Canada. We included only data from a period of exponential growth after removal of individuals for translocation to other areas was stopped, and total population size increased from 116 to 244 (Festa-Bianchet et al. 1998; Engen et al. 2007). Later, the population stabilized, then declined, partly because of intense cougar (Puma concolor) predation (Festa-Bianchet et al. 2006).

Black-browed albatross (Thalassarche melanophrys) is a large (3-4-kg) Procellariiforme, which was studied in the southern colony of Cañon des Sourcils Noirs $\left(49^{\circ} 41^{\prime} \mathrm{S}\right.$, $\left.70^{\circ} 14^{\prime} \mathrm{E}\right)$ at Kerguelen Island in the Southern Ocean, where it has been intensively monitored by capture-recapture techniques since 1980 (Rolland et al. 2009). During the study period, the estimated breeding population size fluctuated around 1,100 breeding pairs (see fig. 2 in Rolland et al. 2009). It starts to breed at 5-14 years of age, although no bird in the current data set bred before the age of 8 years. Pairs breed every year, laying a single egg in late October (Weimerskirch and Jouventin 1998). For a complete life cycle graph, see Rolland et al. (2009).

Demographic data on Columbian ground squirrel (Spermophilus columbianus) were obtained at 1,500 m elevation at the Sheep River Wildlife Sanctuary in the Rocky Mountains of southwestern Alberta, Canada $\left(50^{\circ} \mathrm{N}\right.$, $\left.110^{\circ} \mathrm{W}\right)$. All adults older than 1 year were removed in 1990 , ensuring that, when the study started in 1992, the population was likely far below carrying capacity, with only 4 individuals present; the population reached 57 individuals in 2001 (Engen et al. 2009b). The active season is short, because families start to prepare for the 8-9-month period of hibernation soon after young are weaned in early summer (Dobson et al. 1999). Mean litter size increases from 2.6 offspring among primiparous yearlings to 3.0 offspring among experienced females (Broussard et al. 2008). Columbian ground squirrels are quite long lived for such a small mammal (Dobson and Oli 2001).

Data on the common tern (Sterna hirundo) were collected in a colony on six artificial islands in the Banter See in Wilhelmshaven $\left(58^{\circ} 27^{\prime} \mathrm{N}, 08^{\circ} 07^{\prime} \mathrm{E}\right)$ on the German North Sea coast during a period of steady increase in population size (see fig. 1 in Szostek and Becker 2012). All fledged chicks were marked with subcutaneously im-

Table 1: Data and estimates of key parameters included in the study

\begin{tabular}{|c|c|c|c|c|c|c|}
\hline Species & Locality & Period & $\lambda$ & $\sigma_{\mathrm{d}}^{2}$ & $\sigma_{\mathrm{e}}^{2}$ & G \\
\hline Bighorn sheep & $\begin{array}{l}\text { Ram Mountain, Alberta, } \\
\text { Canada }\end{array}$ & $1981-1992$ & $1.10(1.08-1.12)$ & $.153(.138-.168)$ & $.0027(.0005-.0068)$ & 13 \\
\hline $\begin{array}{l}\text { Black-browed } \\
\text { albatross }\end{array}$ & Kerguelen, Southern Ocean & 1986-1999 & $.94(.91-.96)$ & $.177(.143-.210)$ & $.0028(0-.0063)$ & 14 \\
\hline $\begin{array}{l}\text { Colombian } \\
\text { ground squirrel }\end{array}$ & $\begin{array}{l}\text { Sheep River Wildlife Sanc- } \\
\text { tuary, Alberta, Canada }\end{array}$ & 1992-2001 & $1.17(1.12-1.22)$ & $.347(.300-.399)$ & $.0162(.0049-.0495)$ & 3.5 \\
\hline Common tern & Wilhelmshaven, Germany & $1993-2001$ & $1.05(1.03-1.07)$ & $.163(.147-.179)$ & $.0001(0-.0011)$ & 10 \\
\hline Mauritius kestrel & Mauritius, Indian Ocean & 1990-2001 & $1.03(.97-1.08)$ & $.337(.266-.410)$ & $.0033(0-.0351)$ & 6 \\
\hline Peregrine falcon & Cape Town, South Africa & 1992-2006 & $.98(.94-1.04)$ & . $169(.107-.231)$ & $.0034(.0007-.0070)$ & 9 \\
\hline Red deer & Rum, United Kingdom & 1970-1982 & $1.05(1.04-1.07)$ & $.131(.119-.144)$ & $.0036(.0009-.0075)$ & 12 \\
\hline Roe deer & Trois-Fontaines, France & 1977-2000 & $1.28(1.25-1.31)$ & $.232(.211-.253)$ & $.0034(.0019-.0093)$ & 6 \\
\hline Southern fulmar & Terre Adélie, Antarctica & 1981-1997 & $.98(.95-1.00)$ & $.093(.068-.117)$ & & 17 \\
\hline $\begin{array}{l}\text { Yellow-bellied } \\
\text { marmot }\end{array}$ & $\begin{array}{l}\text { Upper East River Valley, } \\
\text { Colorado }\end{array}$ & $1962-2007$ & $1.10(1.07-1.14)$ & $.994(.904-1.085)$ & $.0351(.0243-.0611)$ & 3 \\
\hline $\begin{array}{r}\text { Wandering } \\
\text { albatross }\end{array}$ & $\begin{array}{l}\text { Possession Island, Indian } \\
\text { Ocean }\end{array}$ & $1981-2007$ & $1.00(.99-1.00)$ & $.096(.089-.103)$ & $.00117(.00003-.00296)$ & 20 \\
\hline White stork & Charente-Maritime, France & 1990-1998 & $.92(.84-.97)$ & $.45(.30-.58)$ & $.0196(.0009-.0541)$ & 8 \\
\hline
\end{tabular}

Note: The $\lambda$ is the population growth rate; $\sigma_{\mathrm{d}}^{2}$ and $\sigma_{\mathrm{e}}^{2}$ are the demographic and environmental variance, respectively; and $G$ is the generation time (years). 
planted transponders (Becker et al. 2008). The probability of resighting of breeders and nonbreeders is close to 1 (Szostek and Becker 2012). Breeding starts at the age of three years. Most females produce only one clutch per breeding season, with a maximum of three eggs (Becker et al. 2001). For a description of the life cycle, see Szostek and Becker (2012).

Mauritius kestrels (Falco punctatus) became extinct in the Bambous mountain range in eastern Mauritius, Indian Ocean, by the late 1950s. A successful reintroduction program that started at the end of the 1980s caused a rapid increase in population during the 1990s until an equilibrium population size was reached of approximately 40 breeding pairs (Sutherland and Norris 2002). Since the onset of the introduction program, almost all individuals in the population have been color-ringed, enabling the collection of detailed individual-based demographic data (Nicoll et al. 2003, 2004; Burgess et al. 2008). In our study, we used data from the period 1990-2001.

Peregrine falcons (Falco peregrinus) were studied in an area covering Cape Town, Table Mountain, and the Cape Peninsula $\left(34^{\circ} 0^{\prime} \mathrm{S}, 18^{\circ} 25^{\prime} \mathrm{E}\right)$ between 1989 and 2008 , during which period the number of breeding pairs increased from 16 to 78 . The birds were ringed either as nestlings or after capture as newly established breeders and received a unique combination of color metal rings and a numbered South African Bird Ringing Unit (University of Cape Town) ring. Peregrines breed between September and December, and all known territories were visited at least once during this period to establish whether the resident breeding pair was still present or whether one of the old birds had been replaced by a new breeder. The resighting probability of breeding birds was close to 1 .

Red deer (Cervus elaphus) have been studied at the Island of Rum, Scotland $\left(57^{\circ} 01^{\prime} \mathrm{N}, 6^{\circ} 17^{\prime} \mathrm{W}\right)$ for several decades. We included data only from the period 1970-1982. During most of this period, the population was recovering from the cessation of harvesting in 1972 (see fig. 1 in Coulson et al. 2004). Red deer females on Rum give birth to a single calf from 3 years of age onward (Clutton-Brock et al. 1982).

Roe deer (Capreolus capreolus) were studied in the forest of Trois-Fontaines in northeastern France $\left(48^{\circ} 43^{\prime} \mathrm{N}\right.$, $\left.2^{\circ} 61^{\prime} \mathrm{W}\right)$, where an enclosed population has been intensively monitored by capture-recapture techniques since 1976 (Gaillard et al. 1993, 1998). Roe deer is a small cervide species with a litter size of up to 3 offspring. The population in Trois-Fontaines is productive, with all 2-year-old females breeding in most years and almost all females producing twins every year (Gaillard et al. 1998). During the study period, the population fluctuated between 154 and 433 individuals (Gaillard et al. 2003) and was likely to be kept below the carrying capacity through harvesting (Gaillard et al. 1993).

Southern fulmars (Fulmarus glaicialoides), a mediumsized (700-1,200-g) cliff-nesting fulmarine petrel, were studied using capture-recapture techniques on Ile des Pétrels, Pointe Géologie Archipelago $\left(66^{\circ} 40^{\prime} \mathrm{S}, 140^{\circ} 01^{\prime} \mathrm{E}\right)$, Terre Adélie, Antarctica, from 1963 onwards by means of individually ringed birds (Berman et al. 2009). Southern fulmars are highly philopatric, and if a bird was not observed between two breeding seasons, it was assumed that it did not reproduce. We included the period 1981-1997 in our analyses to ensure reasonable numbers of knownaged birds as well as to allow sufficient time for recruits to return. During that period, the population showed an increase but with relatively large annual fluctuations in the number of breeding pairs (see fig. 1a in Jenouvrier et al. 2003).

Yellow-bellied marmots (Marmota flaviventris) are large diurnal burrow-dwelling rodents that live in mountain regions of western North America and hibernate from September or October to April or May. The critical factor determining winter survival and subsequent reproductive success is the amount of fat accumulated before hibernation (Melcher et al. 1989). Survival and reproduction are affected by the length of the active season, which shows substantial annual variation associated with changes in onset and termination of snow cover (Armitage and Downhower 1974; Schwartz et al. 1998; Ozgul et al. 2010). We included data collected during the period 1962-2007 from a population living in a subalpine habitat in the Upper East River Valley ( $38^{\circ} 57^{\prime} \mathrm{N} 106^{\circ} 59^{\prime} \mathrm{W}$ ), Colorado (for time series of population fluctuations, see fig. 1c in Ozgul et al. 2010).

Wandering albatrosses (Diomedea exulans) have been studied using capture-recapture techniques on Possession Island, Crozet Archipelago, $\left(46^{\circ} \mathrm{S}, 52^{\circ} \mathrm{E}\right)$ in the southeastern part of the Indian Ocean since 1960. The wandering albatross is a large Procellariforme $(9-12 \mathrm{~kg})$, matures late (8-10 years of age), and produces a maximum of a single offspring per breeding attempt every 2 years (Weimerskirch et al. 1987, 1997; Jouventin and Dobson 2002; Lecomte et al. 2010). In our analyses, we used data from 1981-1997 during a period with increasing population size (see fig. 5 in Engen et al. 2005) to ensure reasonable numbers of known-aged birds as well as allowing sufficient time for recruits to return.

White stork (Ciconia ciconia) is a large wading bird species that has been studied using capture-recapture techniques in Charente-Maritime in western France $\left(45^{\circ} \mathrm{N}\right.$, $1^{\circ} \mathrm{W}$ ). This population was reestablished in 1978 and subsequently showed a rapid increase in population size (Barbraud et al. 1999), which was influenced by immigrants from surrounding areas. During winter, individuals from 
this population migrate to the western part of Sahel in Africa. The white stork builds large, perennial nests either in natural nest sites or at artificial platforms that are most commonly located close to human settlements and therefore are relatively easy to find and to observe during the breeding period. Most white stork start breeding when they are 3 or 4 years old (Nevoux et al. 2007) and produce, on average, 3.4 fledglings per nest (Barbraud et al. 1999). Adult survival is high (mean, 0.78). Temporal variation in survival is dependent on rainfall at the wintering grounds (Nevoux et al. 2008), which may also influence annual variation in numbers of breeding pairs (Sæther et al. 2006).

\section{Results}

First, we examined how individuals of different ages contribute to the total reproductive value of the population. In all cases, the age-specific component of total reproductive value decreased with increasing age (fig. 1). In contrast, there were large interspecific differences in how individual reproductive value decreased with age (fig. 2), with a significant curvilinear relationship in six species. Therefore, age classes consisting of individuals with large contributions to future generations were not necessarily those that contributed most to the total reproductive value, because the latter was more strongly dependent on the stable age distribution of the population.

The stochastic components of population dynamics were related to the position of the species along the slowfast life-history continuum. Both demographic (fig. 3a) and environmental (fig. $3 b$ ) variance decreased with generation time, resulting in smaller total variance (eq. [1]) in population growth rates in long-lived species. The ratio of demographic to environmental variance at $N=1$ ranged from 18.89 in white stork to $1,658.30$ in common terns. Because the effect of demographic stochasticity is density dependent (eq. [1]), its contribution to the variance in population fluctuations decreases with increasing population size. However, the population size at which the contribution of demographic and environmental stochasticity to the variance in population growth rate was equal $\sigma_{\mathrm{e}}^{2}=\sigma_{\mathrm{d}}^{2} / N$ differed strongly among species, independent of the position along the slow-fast life-history continuum. In four bird species (common tern, Mauritius kestrel, southern fulmar, and wandering albatross) the major contribution to the population fluctuations was caused by demographic stochasticity even at population sizes greater than 250 individuals.

Stochastic factors were then partitioned into contributions from different vital rates. In all but one species, the contribution from fecundity (fig. $3 d, 3 g$ ) to the stochastic components was larger than the contribution from survival (fig. $3 c, 3 f$ ); the exceptions were the demographic variance of the common tern and the environmental variance of red deer. The stochastic variation in fecundity and survival as well as the covariation between them, caused either by demographic or environmental stochasticity, all decreased with generation time (fig. $3 c-3 h$ ).

We then analyzed whether the pattern of age-specific variation in stochastic influences on population growth was related to life history. The influence of demographic stochasticity in age class $i \sigma_{\mathrm{di}}^{2}$ on the variance in population growth (eq. [7]) decreased with increasing age, although the rate of decrease differed substantially across species, being nonlinear in four cases (table 2). Age-specific estimates of demographic variance, reflecting the betweenindividual variation in age-dependent fecundity and survival, decreased linearly with age in all species (statistically significant in 5 of 6 mammals, with the Colombian ground squirrel as an exception, and in 2 bird species [southern fulmar, $P=.02$; wandering albatross, $P=.001]$; the decrease was close to statistical significance $[.05<P<.06]$ in the black-browed albatross and white stork). In contrast, there was no consistent age-specific pattern in the contribution of environmental variance $\tau_{\mathrm{ei}}^{2}$ (eq. [9]) to fluctuations in population size (although there was a decrease in $\tau_{\mathrm{ei}}^{2}$ with age in 6 species; table 2), in the betweenindividual variation in production of new recruits $(P>$ $.12)$, or in survival $(P>.12)$ caused by environmental stochasticity.

Age-specific variation in the contribution to population growth was affected by large differences among species in the pattern of age-dependent survival. To account for these differences, we scaled age classes relative to generation time $G$, following Hamilton (1966). This facilitates a comparison of age-specific patterns between species with different life-history characteristics. There were large interspecific differences in the stage of the life cycle relative to generation time that had the strongest influence on population dynamics (fig. 4). For the contribution to total reproductive value (fig. $4 a$ ) and to demographic variance (fig. $4 b$ ), the larger variation among species was found in the younger age classes (relative to generation time). In contrast, there were large interspecific differences in the contribution from the different stages of the life cycle to environmental stochasticity in population dynamics (fig. $4 c$ ).

Finally, we analyzed how the stage of the life cycle that most strongly affected variation in population growth depended on the position of the species along the slow-fast continuum of life-history variation, measured by generation time $G$. We calculated for each species the age relative to $G$ at which $50 \%$ of the total reproductive value and of the two stochastic components of the variance in population growth rate were reached and related these quantities to generation time. If the slope of this regression line is less than 1 , the relative contribution of younger age 

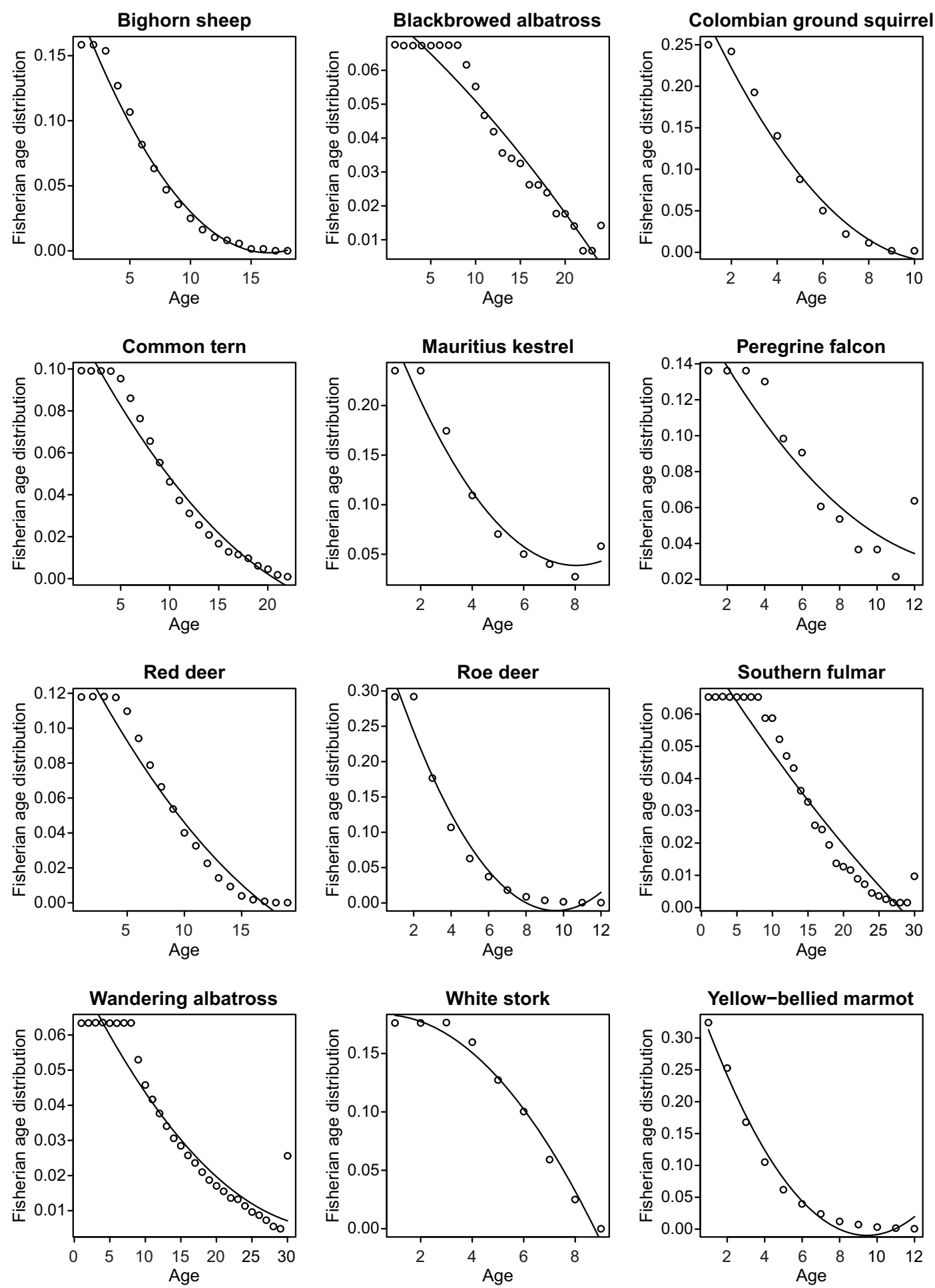

Figure 1: Interspecific differences in age-specific variation in the contribution to the total reproductive value of the population. The Fisherian age distribution refers to the reproductive value in age class $i v_{i}$ scaled so that $\sum u_{i}=1$ and $v u=\sum u_{i} v_{i}=1$, where $u$ is the stable age distribution for the deterministic model. This shows the relative contribution of the different age classes to the total reproductive value of the population. 

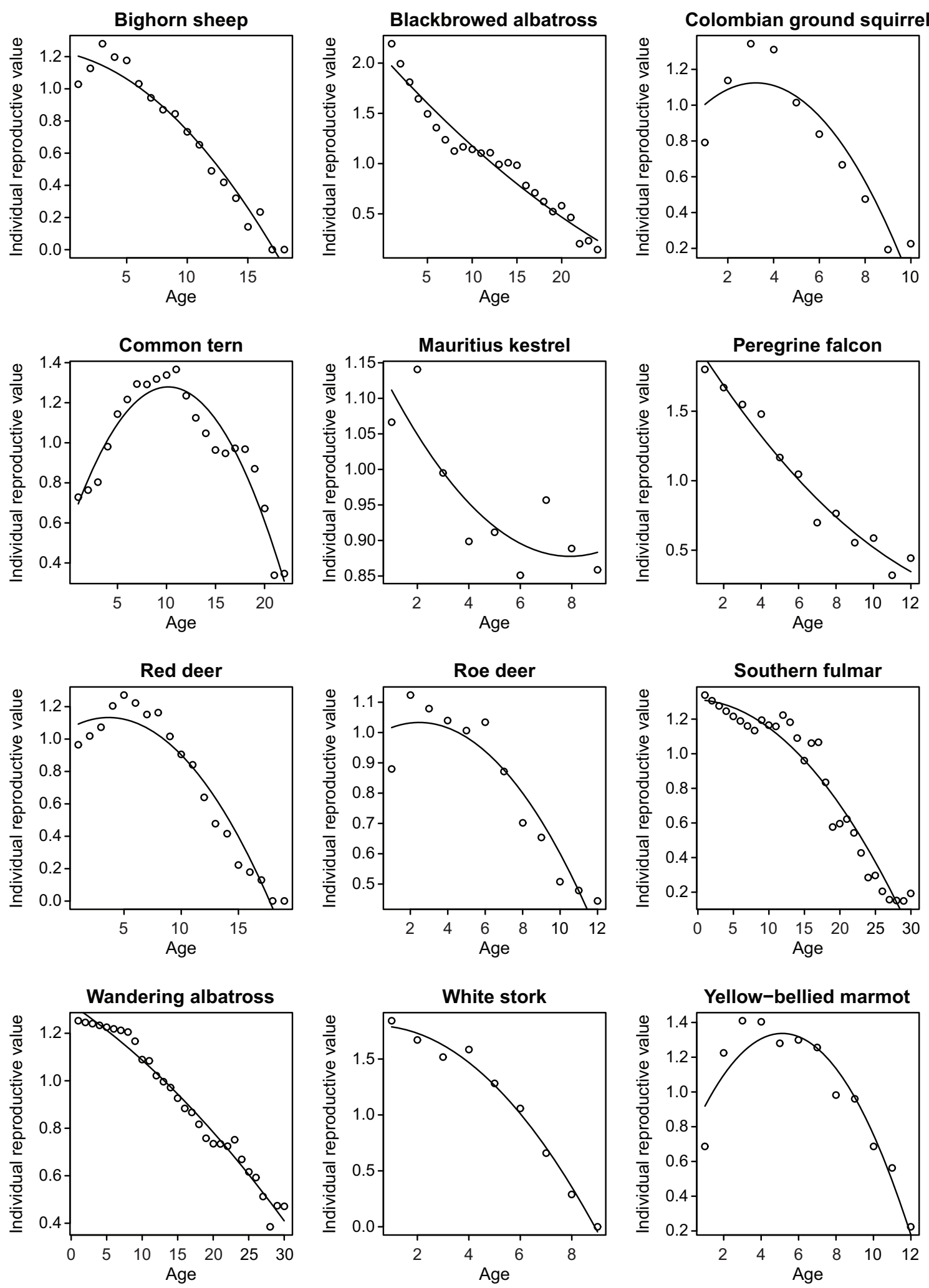

Figure 2: Interspecific differences in age-specific individual reproductive value. 



Figure 3: Interspecific variation in demographic $\sigma_{\mathrm{d}}^{2}(a)$ and environmental variance $\sigma_{\mathrm{e}}^{2}(b)$ as well as the contributions to $\sigma_{\mathrm{d}}^{2}(c-e)$ and $\sigma_{\mathrm{e}}^{2}$ $(f-h)$ from survival, fecundity, and the covariance between them in relation to generation time $G$. The triangles represent mammals, and the circles represent birds.

classes increases with generation time. In contrast, if the slope is larger than 1 , the relative contribution of the younger age classes decreases toward the slow end of the lifehistory continuum. The slopes for the total reproductive value of the population (fig. $5 a$ ) and for the total demographic variance (fig. $5 b$ ) were less than 1 , revealing that the contribution of earlier stages within the life cycle to stochastic population growth rate was greater in longlived than in short-lived species. In contrast, the slope for the environmental variance (fig. $5 c$ ) did not differ from unity, indicating that environmental stochasticity at different life-history stages has similar effects on population fluctuations per generation.

\section{Discussion}

Our study has shown that, after accounting for fluctuations in the age distribution by analyzing fluctuations in the 
Table 2: Interspecific variation in age-specific individual contributions to demographic $\sigma_{\mathrm{d}}^{2}$ and environmental $\sigma_{\mathrm{e}}^{2}$ variance, as well as components due to variation in adult survival and fecundity $(y)$, modeled as a linear $\left(y=a+b_{1} x\right)$ or curvilinear $\left(y=a+b_{1} x+b_{2} x^{2}\right)$ function of age $x$

\begin{tabular}{|c|c|c|c|c|c|c|c|c|c|}
\hline \multirow[b]{2}{*}{ Species, stochasticity } & \multicolumn{3}{|c|}{ Total } & \multicolumn{3}{|c|}{$\begin{array}{l}\text { Components } \\
\text { due to survival }\end{array}$} & \multicolumn{3}{|c|}{$\begin{array}{l}\text { Components } \\
\text { due to fecundity }\end{array}$} \\
\hline & $a$ & $b_{1}$ & $b_{2}$ & $a$ & $b_{1}$ & $b_{2}$ & $a$ & $b_{1}$ & $b_{2}$ \\
\hline \multicolumn{10}{|l|}{ Bighorn sheep: } \\
\hline$\sigma_{d}^{2}$ & .0201 & $-.0011^{* * *}$ & & .0066 & $-.0004^{* * *}$ & & .0014 & $-.0007^{* *}$ & \\
\hline$\sigma_{e}^{2}$ & .0004 & -.00002 & & -.00003 & .000001 & & .0005 & $-.00003^{* * *}$ & \\
\hline \multicolumn{10}{|l|}{ Black-browed albatross: } \\
\hline$\sigma_{d}^{2}$ & -.010 & $-.0033^{* *}$ & $-.0001^{* *}$ & -.0037 & $.0015^{*}$ & $.00001^{* *}$ & -.0060 & $-.0018^{*}$ & -.00006 \\
\hline$\sigma_{e}^{2}$ & -.00005 & $.0002^{*}$ & $.000006^{*}$ & .00001 & .0000 & & .00000 & .0000 & \\
\hline \multicolumn{10}{|c|}{ Columbian ground squirrel: } \\
\hline$\sigma_{d}^{2}$ & .090 & $-.0088^{* * *}$ & & .0859 & $-.0201^{* *}$ & $.0011^{* *}$ & .0379 & -.0030 & \\
\hline$\sigma_{e}^{2}$ & .005 & $-.0005^{* *}$ & & .0021 & $-.00056^{*}$ & $.00004^{*}$ & .0020 & -.0002 & \\
\hline \multicolumn{10}{|l|}{ Common tern: } \\
\hline$\sigma_{d}^{2}$ & .0146 & $-.0006^{* * *}$ & & .0101 & $-.0005^{* *}$ & & -.0005 & $.0009^{* *}$ & $-.00004^{* *}$ \\
\hline$\sigma_{e}^{2}$ & .00005 & .00000 & & .00007 & $-.000004^{*}$ & & .0002 & $-.00008^{*}$ & \\
\hline \multicolumn{10}{|l|}{ Mauritius kestrel: } \\
\hline$\sigma_{d}^{2}$ & .065 & -.0045 & & .0113 & -.0004 & & .0498 & -.0037 & \\
\hline$\sigma_{e}^{2}$ & .0003 & -.0001 & & .00005 & -.00003 & & .00001 & .0000 & \\
\hline \multicolumn{10}{|l|}{ Red deer: } \\
\hline$\sigma_{d}^{2}$ & .0132 & $-.0006^{* * *}$ & & .0062 & $-.0003^{* *}$ & & -.0028 & $.0021^{* * *}$ & $-.00017^{* * *}$ \\
\hline$\sigma_{e}^{2}$ & .0004 & -.00002 & & .0002 & $-.000005^{*}$ & & .00004 & $-.00003^{* *}$ & $-.000001^{*}$ \\
\hline \multicolumn{10}{|l|}{ Roe deer: } \\
\hline$\sigma_{d}^{2}$ & .057 & $-.0051^{*}$ & & .0188 & $-.0017^{*}$ & & .0376 & $-.0033^{*}$ & \\
\hline$\sigma_{e}^{2}$ & .0007 & -.00005 & & .0003 & $.00003^{*}$ & & .0009 & $-.00008^{*}$ & \\
\hline \multicolumn{10}{|l|}{ Peregrine falcon: } \\
\hline$\sigma_{d}^{2}$ & .0257 & -.0001 & & .0057 & -.0001 & & .0209 & -.00016 & \\
\hline$\sigma_{e}^{2}$ & -.0012 & .0002 & & -.0001 & .000002 & & .0005 & .00000 & \\
\hline \multicolumn{10}{|l|}{ Southern fulmar: } \\
\hline$\sigma_{d}^{2}$ & -.0036 & $-.0014^{* *}$ & $-.00004^{* *}$ & .0249 & -.00009 & & -.0026 & $.00094^{*}$ & $-.00003^{* *}$ \\
\hline$\sigma_{e}^{2}$ & -.0001 & .00000 & & -.00009 & .00000 & & -.00016 & $.00004^{* *}$ & $-.000001^{*}$ \\
\hline \multicolumn{10}{|l|}{ Wandering albatross: } \\
\hline$\sigma_{d}^{2}$ & .0040 & -.00003 & & .0018 & -.00003 & & -.0004 & $.0005^{*}$ & $.00002^{*}$ \\
\hline$\sigma_{e}^{2}$ & .00000 & .000000 & & .00000 & .0000 & & .00000 & .00000 & \\
\hline \multicolumn{10}{|l|}{ White stork: } \\
\hline$\sigma_{d}^{2}$ & -.1200 & $.0668^{* *}$ & $-.0055^{* *}$ & .0249 & -.0023 & & -.1013 & $.0506^{* *}$ & $-.0039^{* *}$ \\
\hline$\sigma_{e}^{2}$ & .0029 & .0001 & & .0044 & .00005 & & .0010 & .00018 & \\
\hline \multicolumn{10}{|l|}{ Yellow-bellied marmot: } \\
\hline$\sigma_{d}^{2}$ & .4375 & $-.0869^{* * *}$ & $.0042^{* *}$ & .1897 & $-.0415^{* * *}$ & $.00215^{* *}$ & .1883 & $-.0339^{* * *}$ & $.0015^{* * *}$ \\
\hline$\sigma_{e}^{2}$ & .0183 & $-.0038^{* * *}$ & $.0002^{* *}$ & .0046 & $-.00097^{* * *}$ & $.00005^{* *}$ & .0078 & $-.0016^{* * *}$ & $.00008^{* * *}$ \\
\hline
\end{tabular}

total reproductive value, the relative contributions to stochastic population growth of age-specific variation in recruitment and survival varied predictably with life history in birds and mammals (figs. 3, 5). Stochastic influences on annual changes in population size decreased toward the slow end of the slow-fast life-history continuum (fig. 3 ). Early age classes contributed relatively more to the total reproductive value and demographic variance in slow species than in fast species, whereas environmental stochas- ticity affected a larger proportion of the life stages in all species, independent of life history (figs. 4, 5).

Reproductive value tended to increase with age to a peak before decreasing (fig. 2), similar to the pattern found in most birds and mammals (Caughley 1967; Newton and Rothery 1997; Haridas and Tuljapurkar 2007; Sæther et al. 2007; Bouwhuis et al. 2011), including man (Hamilton 1966; Keyfitz and Caswell 2005). In contrast, the Fisherian age distribution that describes the relative contribution of 


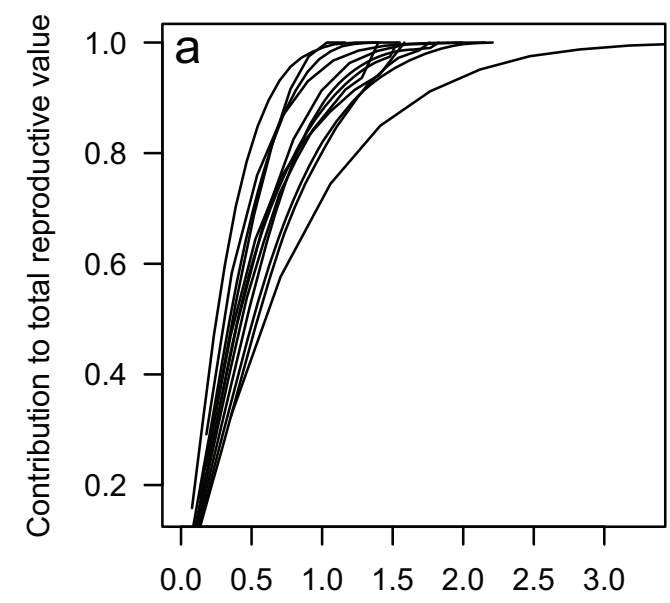

Relative age

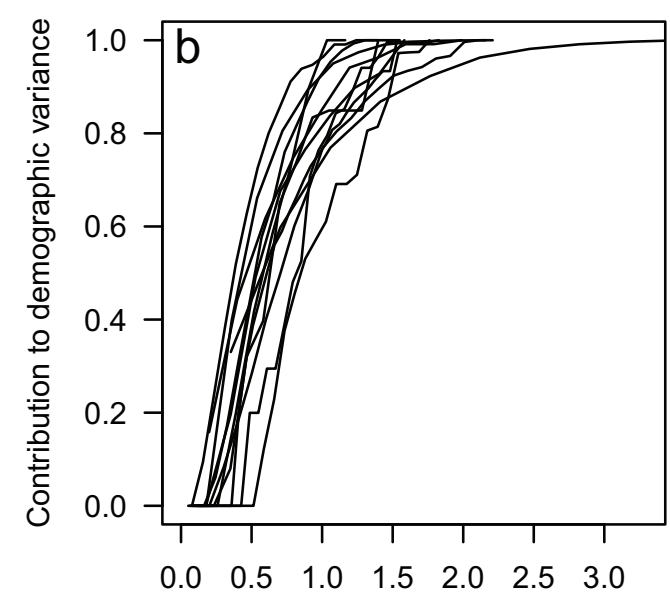

Relative age

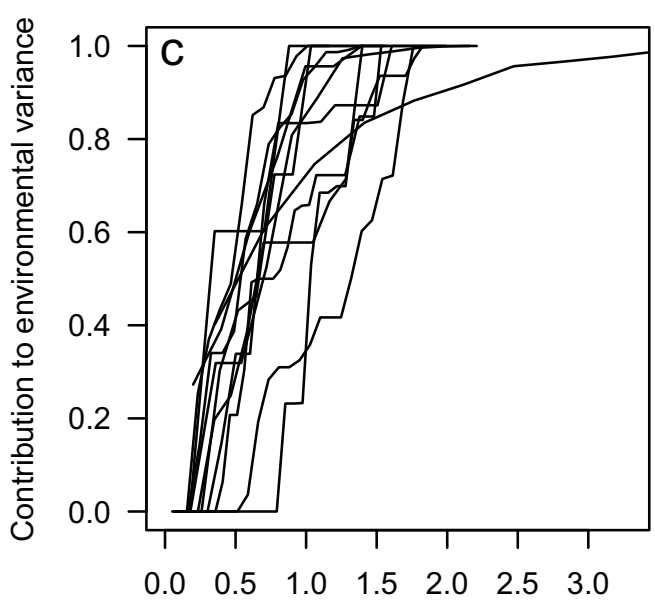

Relative age different age classes to the total reproductive value of the population showed a strict decrease with age (fig. 1), reflecting the influence of the stable age distribution. After accounting for the effects of generation time, a larger proportion of the total reproductive value of the population was located at earlier life-history stages in long-lived species than in short-lived species (fig. $5 a$ ). Therefore, demographic variation in early age classes (relative to generation time) has a particularly strong influence on the total reproductive value of populations of slow species.

Stochastic influences on population dynamics depended on life history. Both demographic and environmental variance decreased with generation time (fig. 3) and resulted in decreased total stochasticity in population dynamics toward the slow end of the life-history continuum. For demographic stochasticity, this is in accordance with previous results for birds (Sæther et al. 2004, 2005), although in density-dependent bird populations, environmental variance was independent of life history (Sæther et al. 2005). This difference may be attributable to a larger influence of environmental stochasticity on populations near carrying capacity. Alternatively, environmental variance may have been overestimated in density-regulated populations by Sæther et al. (2005), because stochastic variation in population size due to fluctuations in age structure was only partly taken into account. Accordingly, in several populations in this study, estimates of environmental variance were small (fig. $3 b$ ). As a consequence, demographic stochasticity was the major stochastic factor affecting population dynamics even at relatively large population sizes. In particular, when annual adult survival approaches 50\%, the contribution of random variation in survival to the demographic variance will be particularly large, because the variance $P(1-P)$ in adult survival peaks at mean survival $P=.5$ (Gaillard and Yoccoz 2003; Morris and Doak 2004). Thus, lower random variation in survival among individuals is an important contributor to the reduction of demographic stochasticity in long-lived species, reducing stochastic influences on population dynamics at the slow end of the life-history continuum.

The pattern of variation in the contribution of different age classes to the stochastic effects on population dynamics (table 2; fig. 4b, 4c) also showed life-history correlates. The larger contributions from demographic stochasticity (fig.

Figure 4: Age-specific variation in the cumulative contribution to the total reproductive value $(a)$ and the stochastic components caused by demographic $(b)$ and environmental stochasticity $(c)$ after correcting for generation time $G$. For each species, the cumulative proportion of the total reproductive value as well as demographic and environmental stochasticity accumulated at different age classes, scaled by generation time $G$, is plotted. 

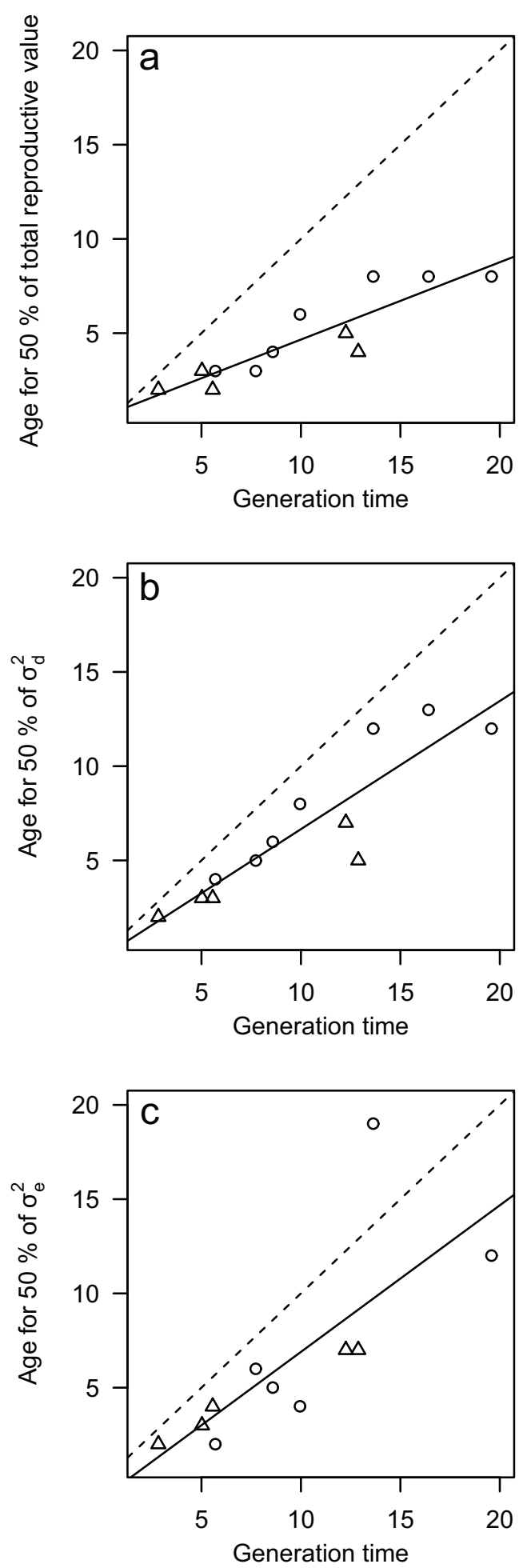

Figure 5: The age for 50\% of total contribution to the total reproductive value and the stochastic components in relation to generation time $G$. The age at which $50 \%\left(A_{50}\right)$ of the total reproductive value of the population $(a)$ and the demographic $(b)$ and environmental (c) variance in the population growth rate is accumulated in relation to the generation time $G$ of mammal (triangles) and
$4 b)$ occurred in age classes with high reproductive values (fig. 2). The impact of younger age classes on demographic variance was particularly strong in long-lived species, so that early life stages (relative to generation time) contributed more to the total reproductive value of the population (fig. $5 a$ ) as well as to demographic stochasticity (fig. $5 b$ ) toward the slow end of the life-history continuum. These age-specific patterns were caused by the combined effect of two factors. First, at the stable age distribution, a large proportion of individuals was in the younger age classes and hence made a large contribution to total demographic variance (eq. [8]). Second, production of new recruits showed an age-specific decrease after a peak near age at maturity in all species (fig. 2). This suggests that, at older ages in slow species, the variation between individuals in reproductive success (fig. $3 a, 3 c, 3 d$ ) was reduced because of senescent effects on vital rates (Rebke et al. 2010), perhaps through a cost of reproduction at early ages (Kirkwood 1977; Benton and Grant 1999) or because of reduced individual variation in reproduction or survival through increased experience or selective mortality of poor-quality individuals (Nussey et al. 2011). Jones et al. (2008) showed that the rate of age-specific decline in the number of recruits produced by females decreased with generation time, probably because of relatively larger reproductive investment at young ages in short-lived species (Péron et al. 2010). However, in spite of this steeper age-specific decrease in reproductive success in short-lived species, after accounting for generation time, the older age classes of fast species still make relatively larger contributions to total reproductive value and demographic variance than older age classes of slow species (fig. $5 a, 5 b$ ). Accordingly, in the relatively long-lived common tern, Ezard et al. (2006) found that the youngest age classes contributed the most to variation in population growth rate. Furthermore, these patterns did not differ between birds and mammals, indicating that the lack of short-lived bird species with high demographic stochasticity (Sæther et al. 2004) in the data set (table 1) did not influence the overall relationship between life history and population dynamics.

In contrast, environmental stochasticity affected a larger part of the life cycle simultaneously in the same year (fig. $5 c$ ). The covariance among demographic traits at different

bird (circles) species. The dashed line has a slope of 1 . The equations for the regression lines are mean $( \pm \mathrm{SE}) A_{50}=0.41 \pm 0.06 G+$ $0.56, r^{2}=0.81, P<.0001, n=12$ for the total reproductive value and $A_{50}=0.68 \pm 0.10 G+0.86, r^{2}=0.81, P<.0001, n=12$ and $A_{50}=0.78 \pm 0.23 G+0.12, r^{2}=0.63, P=.008, n=10$ for demographic and environmental variance, respectively. The slope was less than 1 for the total reproductive value $(P<.0001)$ and the demographic stochasticity $(P=.002)$, but not so for the environmental stochasticity $(P=.45)$. 
ages may then represent an important component of the stochastic contributions to environmental variance in $\lambda$ (Tuljapurkar 1982a, 1990; Benton et al. 1995; Tuljapurkar et al. 2003; Morris et al. 2006, 2008). This environmental covariance spreads the demographic effects of environmental fluctuations across more age classes (fig. 4c). As a consequence, the effects of environmentally induced fluctuations in different age classes (scaled to generation time) are independent of life history (fig. $5 c$ ). Consequently, the effects of stochastic variation in the environment on population growth of species with long generation times are not reduced by negative environmental covariances among different stages of the life cycle (e.g., Morris and Doak 2004 and Morris et al. 2008). Accordingly, analyses of agedependent influences on demography of environmental covariates in two long-lived seabirds revealed similar effects in the youngest and in the oldest age classes (Oro et al. 2010; Pardo et al. 2013). Analyses of the dynamics of four of the mammals included in this study (bighorn sheep, Columbian ground squirrel, roe deer, and yellowbellied marmot) also revealed only minor influences of temporal autocorrelation in the environmental noise on fluctuations in the sizes of these populations (Engen et al. 2013). This indicates that the autocorrelations among life stages in the effects of environmental stochasticity on population growth (figs. $4 c, 5 c$ ) were little influenced by temporal trends in key environmental covariates.

Elasticity analyses of matrix projection models measure the effects of proportional changes in demographic transitions on the population growth rate (Caswell 2001). Comparative analyses of responses of populations to perturbations of different vital rates based on variation in elasticities within the life cycle have revealed that elasticity values may differ widely among age or stage classes, dependent on the structure of the life cycle (Caswell 1996; de Kroon et al. 2000). In mammals, perturbations of reproductive rates around age at maturity have a strong influence on population growth rate (Heppell et al. 2000; Oli and Dobson 2003). Furthermore, temporal variability and elasticity tend to be negatively related (Pfister 1998; Sæther and Bakke 2000; Gaillard and Yoccoz 2003). Our approach to analysis of the contribution of different age classes to the total reproductive value of the population is similar to elasticity analyses, because the elasticity of fecundity and survival at age $i$ are $v_{1} u_{i}$ and $v_{i+1} u_{i}$, respectively. Although these elasticity analyses can also be extended to age-specific influences of environmental stochasticity on the stochastic growth rate (Haridas and Tuljapurkar 2005), the use of individual reproductive values enables us to separate demographic and environmental stochasticity. Our results reveal that these two stochastic factors have different age-specific effects on the temporal variation in population growth rates (figs. 4, 5). Whereas the effect of demographic stochasticity tends to arise from age classes with high reproductive values (figs. 1,2) and hence large elasticities, the influence of environmental stochasticity is more affected by correlated environmental effects spread more evenly across the life cycle (figs. $4 c, 5 c$ ). Thus, the sensitivity of population growth rate to environmental stochasticity will be less influenced by variability in a few life stages and is less likely to be related to age-specific variation in elasticity than the demographic variance.

Our findings substantially improve our ability to identify critical stages of the life cycle that need to be monitored closely to predict future population trends when long time series are not available. Our results suggest that recovery of declining populations of long-lived species should be especially affected by demographic changes at early life-history stages (figs. $4 a, 5 a$ ). These analyses also show that effects of environmental fluctuations on the population dynamics arise over larger parts of the life cycle than those affecting the long-term changes in mean population size, as revealed by the Fisherian age distribution (fig. 1). This implies that some critical age classes are particularly vulnerable to demographic perturbations, such as those due to human activities. In long-lived species, these perturbations will affect many age classes (figs. $4 c, 5 c$ ), which is likely to result in delayed responses in the dynamics because of covariation in environmental stochasticity producing fluctuations in age structure. In contrast, short-lived species will show far more immediate responses to environmental perturbations, because changes in population size will be caused by demographic variations across most parts of the life cycle (fig. 5c). Finally, age-specific variation in reproductive values is also likely to influence the rate of evolutionary change in age-structured populations (Hamilton 1966; Charlesworth 1972, 1994; Engen et al. 2009a). Thus, analyses of fluctuations in the reproductive value of the population may provide a common framework for analyses of demographic responses to environmental changes at both ecological and evolutionary time scales (Engen et al. 2011).

\section{Acknowledgments}

We are extremely to grateful to B. Sheldon for critical discussion and to two reviewers for comments that greatly improved the presentation of the results. This study was financed by a grant from the European Research Council (268562-STOCHPOP). 


\section{Literature Cited}

Ariño, A., and S. L. Pimm. 1995. On the nature of population extremes. Evolutionary Ecology 9:429-443.

Armitage, K. B., and J. F. Downhower. 1974. Demography of yellowbellied marmot populations. Ecology 55:1233-1245.

Barbraud, C., J. C. Barbraud, and M. Barbraud. 1999. Population dynamics of the white stork Ciconia ciconia in western France. Ibis 141:469-479.

Becker, P. H., T. H. G. Ezard, J. D. Ludwigs, H. Sauer-Gurth, and M. Wink. 2008. Population sex ratio shift from fledging to recruitment: consequences for demography in a philopatric seabird. Oikos 117:60-68.

Becker, P. H., H. Wendeln, and J. Gonzalez-Solis. 2001. Population dynamics, recruitment, individual quality and reproductive strategies in common terns Sterna hirundo marked with transponders. Ardea 89:241-252.

Benton, T. G., and A. Grant. 1999. Optimal reproductive effort in stochastic, density-dependent environments. Evolution 53:677688.

Benton, T. G., A. Grant, and T. H. Clutton-Brock. 1995. Does environmental stochasticity matter? analysis of red deer life-histories on Rum. Evolutionary Ecology 9:559-574.

Berman, M., J.-M. Gaillard, and H. Weimerskirch. 2009. Contrasted patterns of age-specific reproduction in long-lived seabirds. Proceedings of the Royal Society B: Biological Sciences 276:375-382.

Bouwhuis, S., R. Choquet, B. C. Sheldon, and S. Verhulst. 2011. The forms and fitness cost of senescence: age-specific recapture, survival, reproduction, and reproductive value in a wild bird population. American Naturalist 179:E15-E27.

Broussard, D. R., F. S. Dobson, and J. O. Murie. 2008. Previous experience and reproductive investment of female Columbian ground squirrels. Journal of Mammalogy 89:145-152.

Burgess, M. D., M. A. C. Nicoll, C. G. Jones, and K. Norris. 2008. Restricted dispersal reduces the strength of spatial density dependence in a tropical bird population. Proceedings of the Royal Society B: Biological Sciences 275:1209-1216.

Caswell, H. 1978. A general formula for the sensitivity of population growth rate to changes in life history parameters. Theoretical Population Biology 14:215-230.

. 1996. Second derivatives of population growth rate: calculation and applications. Ecology 77:870-879.

- 2001. Matrix population models. 2nd ed. Sinauer, Sunderland, MA,

Catchpole, E. A., Y. Fan, B. J. T. Morgan, T. H. Clutton-Brock, and T. Coulson. 2004. Sexual dimorphism, survival and dispersal in red deer. Journal of Agricultural Biological and Environmental Statistics 9:1-26.

Caughley, G. 1967. Parameters for seasonally breeding populations. Ecology 48:834-839.

Charlesworth, B. 1972. Selection in populations with overlapping generations. III. Conditions for genetic equilibrium. Theoretical Population Biology 3:377-395.

- 1994. Evolution in age-structured populations. Cambridge University Press, Cambridge.

Clutton-Brock, T. H., F. E. Guinness, and S. D. Albon. 1982. Red deer: behaviour and ecology of two sexes. University of Chicago Press, Chicago.

Cohen, J. 1977. Ergodicity of age structure in populations with Mar- kovian vital rates. III. Finite-state moments and growth rate: an illustration. Advances in Applied Probability 9:462-475.

Cohen, J. E. 1979. Ergodic theorems in demography. Bulletin of the American Mathematical Society 1:275-295.

Coulson, T., E. A. Catchpole, S. D. Albon, B. J. T. Morgan, J. M. Pemberton, T. H. Clutton-Brock, M. J. Crawley, et al. 2001. Age, sex, density, winter weather, and population crashes in Soay sheep. Science 292:1528-1531.

Coulson, T., F. Guinness, J. Pemberton, and T. Clutton-Brock. 2004. The demographic consequences of releasing a population of red deer from culling. Ecology 85:411-422.

Deevey, E. S., Jr. 1947. Life tables for natural populations of animals. Quarterly Review of Biology 22:283-314.

de Kroon, H., J. van Groenendael, and J. Ehrlen. 2000. Elasticities: a review of methods and model limitations. Ecology 81:607-618.

Dobson, F. S., and M. K. Oli. 2001. The demographic basis of population regulation in Columbian ground squirrels. American Naturalist 158:236-247.

. 2007. Fast and slow life histories of mammals. Ecoscience 14:292-299.

Dobson, F. S., T. S. Risch, and J. O. Murie. 1999. Increasing returns in the life history of Columbian ground squirrels. Journal of Animal Ecology 68:73-86.

Engen, S., R. Lande, and B.-E. Sæther. 2009a. Reproductive value and fluctuating selection in an age-structured population. Genetics 183:629-637.

. 2011. Evolution of a plastic quantitative trait in an agestructured population in a fluctuating environment. Evolution 65: 2893-2906.

Engen, S., R. Lande, B.-E. Sæther, and F. S. Dobson. 2009b. Reproductive value and the stochastic demography of age-structured populations. American Naturalist 174:795-804.

Engen, S., R. Lande, B.-E. Sæther, and M. Festa-Bianchet. 2007. Using reproductive value to estimate key parameters in density-independent age-structured populations. Journal of Theoretical Biology 244:208-317.

Engen, S., R. Lande, B.-E. Sæther, and H. Weimerskirch. 2005. Extinction in relation to demographic and environmental stochasticity in age-structured models. Mathematical Biosciences 195:210227.

Engen, S., B.-E. Sæther, K. B. Armitage, D. T. Blumstein, T. H. Clutton-Brock, F. S. Dobson, M. Festa-Bianchet, et al. 2013. Estimating the effect of temporally autoccorrelated environments on the demography of density-independent age-structured populations. Methods in Ecology and Evolution 4:573-584.

Ezard, T. H. G., P. H. Becker, and T. Coulson. 2006. The contributions of age and sex to variation in common tern population growth rate. Journal of Animal Ecology 75:1379-1386.

Festa-Bianchet, M., T. Coulson, J.-M. Gaillard, J. T. Hogg, and F. Pelletier. 2006. Stochastic predation events and population persistence in bighorn sheep. Proceedings of the Royal Society B: Biological Sciences 273:1537-1543.

Festa-Bianchet, M., J.-M. Gaillard, and J. T. Jorgenson. 1998. Massand density-dependent reproductive success and reproductive costs in a capital breeder. American Naturalist 152:367-379.

Fisher, R. A. 1930. The genetical theory of natural selection. Clarendon, Oxford.

Gaillard, J.-M., R. Andersen, D. Delorme, and J. D. C. Linnell. 1998. Family effects on growth and survival of juvenile roe deer. Ecology 79:2878-2889. 
Gaillard, J. M., D. Delorme, J. M. Boutin, G. Vanlaere, B. Boisaubert, and R. Pradel. 1993. Roe deer survival patterns: a comparative analysis of contrasting populations. Journal of Animal Ecology 62: 778-791.

Gaillard, J. M., P. Duncan, D. Delorme, G. van Laere, N. Pettorelli, D. Maillard, and G. Renaud. 2003. Effects of hurricane Lothar on the population dynamics of European roe deer. Journal of Wildlife Management 67:767-773.

Gaillard, J.-M., D. Pontier, D. Allainé, J.-D. Lebreton, J. Trouvilliez, and J. Clobert. 1989. An analysis of demographic tactics in birds and mammals. Oikos 56:59-76.

Gaillard, J. M., A. Viallefont, A. Loison, and M. Festa-Bianchet. 2004. Assessing senescence patterns in populations of large mammals. Animal Biodiversity and Conservation 27:47-58.

Gaillard, J. M., and N. G. Yoccoz. 2003. Temporal variation in survival of mammals: a case of environmental canalization? Ecology 84: 3294-3306.

Gaillard, J. M., N. G. Yoccoz, J. D. Lebreton, C. Bonenfant, S. Devillard, A. Loison, D. Pontier, et al. 2005. Generation time: a reliable metric to measure life-history variation among mammalian populations. American Naturalist 166:119-123.

Goodman, L. A. 1967. Probabilities of extinction for birth-and-death processes that are age-dependent or phase-dependent. Biometrika 54:579-596.

Hamilton, W. D. 1966. The moulding of senescence by natural selection. Journal of Theoretical Biology 12:12-45.

Haridas, C. V., and S. Tuljapurkar. 2005. Elasticities in variable environments: properties and implications. American Naturalist 166: 481-495.

- 2007. Time, transients and elasticity. Ecology Letters 10: 1143-1153.

Heppell, S. S., H. Caswell, and L. B. Crowder. 2000. Life histories and elasticity patterns: perturbation analysis for species with minimal demographic data. Ecology 81:654-665.

Jenouvrier, S., C. Barbraud, and H. Weimerskirch. 2003. Effects of climate on the temporal population dynamics of southern fulmars. Journal of Animal Ecology 72:576-587.

Jones, O. R., J. M. Gaillard, S. Tuljapurkar, J. S. Alho, K. B. Armitage, P. H. Becker, P. Bize, et al. 2008. Senescence rates are determined by ranking on the fast-slow life-history continuum. Ecology Letters 11:664-673.

Jouventin, P., and F. S. Dobson. 2002. Why breed every other year? the case of albatrosses. Proceedings of the Royal Society B: Biological Sciences 269:1955-1961.

Keyfitz, N., and H. Caswell. 2005. Applied mathematical demography. 3rd ed. Springer, New York.

Kirkwood, T. B. L. 1977. Evolution of aging. Nature 270:301-304.

Lande, R., S. Engen, and B.-E. Sæther. 2003. Stochastic population dynamics in ecology and conservation. Oxford University Press, Oxford.

Lande, R., and S. H. Orzack. 1988. Extinction dynamics of agestructured populations in a fluctuating environment. Proceedings of the National Academy of Sciences of the USA 85:7418-7421.

Lecomte, V. J., G. Sorci, S. Cornet, A. Jaeger, B. Faivre, E. Arnoux, M. Gaillard, et al. 2010. Patterns of aging in the long-lived wandering albatross. Proceedings of the National Academy of Sciences of the USA 107:6370-6375.

Leslie, P. H. 1945. On the use of matrices in certain population mathematics. Biometrika 33:183-212.
1948. Some further notes on the use of matrices in population mathematics. Biometrika 35:213-245.

1966. The intrinsic rate of increase and overlap of successive generations in a population of guillemots (Uria aalge Pont). Journal of Animal Ecology 35:291-301.

Lewontin, R. C., and D. Cohen. 1969. On population growth in a randomly varying environment. Proceedings of the National Academy of Sciences of the USA 62:1056-1060.

May, R. M. 1973. Stability in randomly fluctuating versus deterministic environments. American Naturalist 107:621-650.

Melcher, J. C., K. B. Armitage, and W. P. Porter. 1989. Energy allocation by yellow-bellied marmots. Physiological Zoology 62:429448.

Millar, J. S., and R. M. Zammuto. 1983. Life histories of mammals: an analysis of life tables. Ecology 64:631-635.

Morris, W. F., and D. F. Doak. 2004. Buffering of life histories against environmental stochasticity: accounting for a spurious correlation between the variabilities of vital rates and their contributions to fitness. American Naturalist 163:579-590.

Morris, W. F., C. A. Pfister, S. Tuljapurkar, C. V. Haridas, C. L. Boggs, M. S. Boyce, E. M. Bruna, et al. 2008. Longevity can buffer plant and animal populations against changing climate variability. Ecology 89:19-25.

Morris, W. F., S. Tuljapurkar, C. V. Haridas, E. S. Menges, C. C. Horvitz, and C. A. Pfister. 2006. Sensitivity of the population growth rate to demographic variability within and between phases of the disturbance cycle. Ecology Letters 9:1331-1341.

Nevoux, M., J.-C. Barbraud, and C. Barbraud. 2008. Nonlinear impact of climate on survival in a migratory white stork population. Journal of Animal Ecology 77:1143-1152.

Nevoux, M., H. Weimerskirch, and C. Barbraud. 2007. Environmental variation and experience-related differences in the demography of the long-lived black-browed albatross. Journal of Animal Ecology 76:159-167.

Newton, I., and P. Rothery. 1997. Senescence and reproductive value in sparrowhawks. Ecology 78:1000-1008.

Nicoll, M. A. C., C. G. Jones, and K. Norris. 2003. Declining survival rates in a reintroduced population of the Mauritius kestrel: evidence for non-linear density dependence and environmental stochasticity. Journal of Animal Ecology 72:917-926.

- 2004. Comparison of survival rates of captive-reared and wild-bred Mauritius kestrels (Falco punctatus) in a re-introduced population. Biological Conservation 118:539-548.

Nussey, D. H., T. Coulson, D. Delorme, T. H. Clutton-Brock, J. M. Pemberton, M. Festa-Bianchet, and J. M. Gaillard. 2011. Patterns of body mass senescence and selective disappearance differ among three species of free-living ungulates. Ecology 92:1936-1947.

Oli, M. K., and F. S. Dobson. 2003. The relative importance of lifehistory variables to population growth rate in mammals: Cole's prediction revisited. American Naturalist 161:422-440.

Oro, D., R. Torres, C. Rodriguez, and H. Drummond. 2010. Climatic influence on demographic parameters of a seabird varies with age and sex. Ecology 91:1205-1214.

Ozgul, A., D. Z. Childs, M. K. Oli, K. B. Armitage, D. T. Blumstein, L. E. Olson, S. Tuljapurkar, et al. 2010. Coupled dynamics of body mass and population growth in response to environmental change. Nature 466:482-485.

Pardo, D., C. Barbraud, M. Authier, and H. Weimerskirch. 2013. Evidence for an age-dependent influence of environmental vari- 
ations on a long-lived seabird's life history traits. Ecology 94:208220.

Pearl, R., and J. R. Miner. 1935. Experimental studies on the duration of life. XIV. The comparative mortality of certain lower organisms. Quarterly Review of Biology 10:60-79.

Péron, G., O. Gimenez, A. Charmantier, J.-M. Gaillard, and P. A. Crochet. 2010. Age at the onset of senescence in birds and mammals is predicted by early-life performance. Proceedings of the Royal Society B: Biological Sciences 277:2849-2856.

Pfister, C. M. 1998. Patterns of variance in stage-structured populations: evolutionary predictions and ecological implications. Proceedings of the National Academy of Sciences of the USA 95:213218.

Pimm, S. L., and A. Redfearn. 1988. The variability of animal populations. Nature 334:613-614.

Pollard, E. H. 1966. On the use of the direct matrix product in analysing certain stochastic population models. Biometrika 53: 397-415.

Promislow, D. E. L., and P. H. Harvey. 1990. Living fast and dying young: a comparative analysis of life-history variation among mammals. Journal of Zoology 220:417-437.

Rauser, C. L., L. D. Mueller, M. Travisano, and M. R. Rose. 2009. Evolution of aging and late life. Pages 551-584 in T. Garland Jr. and M. R. Rose, eds. Experimental evolution: concepts, methods, and applications of selection experiments. University of California Press, Berkeley.

Rebke, M., T. Coulson, P. H. Becker, and J. W. Vaupel. 2010. Reproductive improvement and senescence in a long-lived bird. Proceedings of the National Academy of Sciences of the USA 107: 7841-7846.

Roff, D. A. 2002. The evolution of life histories. Chapman \& Hall, New York.

Rolland, V., M. Nevoux, C. Barbraud, and H. Weimerskirch. 2009. Respective impact of climate and fisheries on the growth of an albatross population. Ecological Applications 19:1336-1346.

Roughgarden, J. 1979. Theory of population genetics and evolutionary ecology: an introduction. Macmillan, New York.

Royama, T. 1992. Analytical population dynamics. Chapman \& Hall, London.

Schwartz, O. A., K. B. Armitage, and D. Van Vuren. 1998. A 32-year demography of yellow-bellied marmots (Marmota flaviventris). Journal of Zoology 246:337-346.

Stearns, S. C. 1983. The influence of size and phylogeny on patterns of covariation among life-history traits in mammals. Oikos 41: 173-187.

1992. The evolution of life histories. Oxford University Press, Oxford.

Sutherland, W. J., and K. Norris. 2002. Behavioural models of population growth rates: implications for conservation and prediction. Philosophical Transactions of the Royal Society B: Biological Sciences 357:1273-1284.

Szostek, K. L., and P. H. Becker. 2012. Terns in trouble: demographic consequences of low breeding success and recruitment on a common tern population in the German Wadden Sea. Journal of Ornithology 153:313-326.

Sæther, B.-E., and Ø. Bakke. 2000. Avian life history variation and contribution of demographic traits to the population growth rate. Ecology 81:642-653.

Sæther, B.-E., and S. Engen. 2002. Pattern of variation in avian population growth rates. Philosophical Transactions of the Royal Society B: Biological Sciences 357:1185-1195.

Sæther, B.-E., S. Engen, and E. Matthysen. 2002. Demographic characteristics and population dynamical patterns of solitary birds. Science 295:2070-2073.

Sæther, B.-E., S. Engen, A. P. Møller, H. Weimerskirch, M. E. Visser, W. Fiedler, E. Matthysen, et al. 2004. Life-history variation predicts the effects of demographic stochasticity on avian population dynamics. American Naturalist 164:793-802.

Sæther, B.-E., S. Engen, E. J. Solberg, and M. Heim. 2007. Estimating the growth of a newly established moose population using reproductive value. Ecography 30:417-421.

Sæther, B.-E., V. Grøtan, P. Tryjanowski, C. Barbraud, S. Engen, and M. Fulin. 2006. Climate and spatio-temporal variation in the population dynamics of a long-distance migrant, the white stork. Journal of Animal Ecology 75:80-90.

Sæther, B.-E., R. Lande, S. Engen, H. Weimerskirch, M. Lillegård, R. Altwegg, P. H. Becker, et al. 2005. Generation time and temporal scaling of bird population dynamics. Nature 436:99-102.

Tuljapurkar, S., C. C. Horvitz, and J. B. Pascarella. 2003. The many growth rates and elasticities of populations in random environments. American Naturalist 162:489-502.

Tuljapurkar, S. D. 1982a. Population dynamics in variable environments. II. Correlated environments, sensitivity analysis and dynamics. Theoretical Population Biology 21:114-140.

- 1982b. Population dynamics in variable environments. III. Evolutionary dynamics of $r$-selection. Theoretical Population Biology 21:141-165.

. 1990. Population dynamics in variable environments. Springer, New York.

Tuljapurkar, S. D., and S. H. Orzack. 1980. Population dynamics in variable environments. I. Long-run growth rates and extinction. Theoretical Population Biology 18:314-342.

Turelli, M. 1977. Random environments and stochastic calculus. Theoretical Population Biology 12:140-178.

Weimerskirch, H. 1992. Reproductive effort in long-lived birds: agespecific patterns of condition, reproduction and survival in the wandering albatross. Oikos 64:464-473.

Weimerskirch, H., N. Brothers, and P. Jouventin. 1997. Population dynamics of wandering albatross Diomedea exulans and Amsterdam albatross $D$. amsterdamensis in the Indian Ocean and their relationships with long-line fisheries: conservation implications. Biological Conservation 79:257-270.

Weimerskirch, H., J. Clobert, and P. Jouventin. 1987. Survival in five southern Albatrosses and its relationship with their life history. Journal of Animal Ecology 56:1043-1055.

Weimerskirch, H., and P. Jouventin. 1998. Changes in population sizes and demographic parameters of six albatross species breeding on the French sub-Antarctic islands. Pages 84-91 in G. Robertson and R. Gales, eds. Albatross Biology and Conservation. Surrey Beatty, Sydney, Australia.

Associate Editor: Uta Berger Editor: Troy Day 